\title{
Bleeding risk of small intracranial aneurysms in a population treated in a reference center
}

\author{
Risco de sangramento de aneurismas intracranianos pequenos em uma população \\ tratada em um centro de referência
}

\author{
Guilherme LEPSKI', Carlos A. F. LOBÃO', Stella TAYLOR', Paulo M. MESQUITA FILHO'1, Marcos TATAGIBA'
}

\begin{abstract}
Large multicenter studies have shown that small intracranial aneurysms are associated with a minimal risk of bleeding. Nevertheless, other large series have shown that most ruptured aneurysms are, in fact, the smaller ones. In the present study, we questioned whether small aneurysms are indeed not dangerous. Methods: We enrolled 290 patients with newly-diagnosed aneurysms at our institution over a six-year period (43.7\% ruptured). We performed multivariate analyses addressing epidemiological issues, cardiovascular diseases, and three angiographic parameters (largest aneurysm diameter, neck diameter and diameter of the nutrition vessel). Risk estimates were calculated using a logistic regression model. Aneurysm size parameters were stratified according to receiver operating characteristic (ROC) curves. Finally, we calculated odds ratios for rupture based on the ROC analysis. Results: The mean largest diameter for the ruptured versus unruptured groups was $13.3 \pm 1.7 \mathrm{~mm}$ versus $22.2 \pm 2.2 \mathrm{~mm}(\mathrm{p}<0.001)$. Multivariate analysis revealed a positive correlation between rupture and arterial hypertension $(p<0.001)$ and an inverse correlation with all three angiographic measurements (all $p<0.01)$. Aneurysms from the anterior cerebral artery bled more often $(p<0.05)$. According to the ROC curves, at the largest diameter of $15 \mathrm{~mm}$, the sensitivity and specificity to predict rupture were $83 \%$ and $36 \%$, respectively. Based on this stratification, we calculated the chance of rupture for aneurysms smaller than $15 \mathrm{~mm}$ as 46\%, which dropped to 25\% for larger aneurysms. Conclusion: In the population studied at our institution, small aneurysms were more prone to bleeding. Therefore, the need for intervention for small aneurysms should not be overlooked.
\end{abstract}

Keywords: Intracranial aneurysm, rupture.

\section{RESUMO}

Grandes estudos multicêntricos demostram que aneurismas intracranianos pequenos são associados a risco de sangramento mínimo. Outras grandes séries têm evidenciado que aneurismas rotos são em sua maioria os pequenos. Neste estudo questionamos até que ponto os aneurismas pequenos não são perigosos. Métodos: Avaliamos 290 novos casos de aneurismas tratados em nossa instituição durante 6 anos (43,7\% rotos). Realizamos análises multivariadas com aspectos epidemiológicos dos pacientes, doenças cardiovasculares e três parâmetros angiográficos: maior diâmetro, diâmetro do colo e diâmetro do vaso nutridor do aneurisma. Estimativas de risco foram calculadas utilizando-se modelo de regressão logística. Parâmetros do tamanho aneurismático foram estratificados de acordo com curvas ROC. Também calculamos a razão de chances (odds ratios) de ruptura baseadas nas análises das curvas ROC. Resultados: 0 maior diâmetro médio para os grupos de aneurismas rotos e não-rotos foi $13.3 \pm 1.7 \mathrm{~mm}$ e $22.2 \pm 2.2$ ( $p<0.001$ ). Análises multivariadas revelaram uma correlação positiva entre ruptura aneurismática e hipertensão arterial $(p<0.001)$ e uma correlação inversa entre ruptura e as três medidas angiográficas $(p<0.01)$. Aneurismas da artéria cerebral anterior foram os que mais sangraram $(p<0.05)$. Análises das curvas ROC demonstram que no maior diâmetro de $15 \mathrm{~mm}$, a sensibilidade e especificidade para se predizer ruptura são de $83 \%$ e $36 \%$. Baseando-se nessas estratificações, calculamos uma chance de ruptura para aneurismas menores de $15 \mathrm{~mm}$ de $46 \%$ e de $25 \%$ para aneurismas maiores. Conclusão: Na população estudada, aneurismas pequenos são mais propensos a romper. Desta forma, a necessidade de intervenção para aneurismas pequenos não deve ser relevada.

Palavras-chave: Aneurisma intracraniano, ruptura.

Large multicenter studies on unruptured aneurysms have shown a relatively low rupture rate for smaller aneurysms compared with larger ones ${ }^{1,2}$. Nevertheless, controversy on the subject still persists, based on the fact that a high percentage of patients admitted to reference centers with subarachnoidal hemorrhage (SAH) present with aneurysms smaller

${ }^{1}$ Universitätsklinik für Neurochirurgie, Eberhard Karls University, Tübingen, Deutschland.

Guilherme Lepski iD https://orcid.org/0000-0002-9030-4192; Carlos Augusto Ferreira Lobão iD https://orcid.org/0000-0001-7789-1663;

Paulo M. Mesquita Filho (iD) https://orcid.org/0000-0003-1375-9203; Stella Taylor (iD https://orcid.org/0000-0001-7186-8868; Marcos Tatagiba iD https://orcid.org/0000-0002-1627-9937

Correspondence:Carlos A. F. Lobão; Eberherd-Karls University - Neurosurgery Hoppe-Seyler-Str.4Tuebingen 72072,Germany; E-mail: caflobao@yahoo.com.br Conflict of interest: There is no conflict of interest to declare.

Received 28 August 2018; Received in final form 16 September 2018; Accepted 05 February 2019. 
than $5 \mathrm{~mm}^{3,4,5,6,7,8}$. The prevalence of intracranial aneurysms varies from $3.7 \%$ in prospective autopsy studies to $6.0 \%$ in prospective angiographic studies ${ }^{9}$. Moreover, they lead to a relatively high rate of morbidity-mortality, with a rate of $\mathrm{SAH}$ of about $1.4 \%$ per year ${ }^{10}$, which is in turn associated with a mortality rate of up to $50 \%{ }^{11}$; furthermore, half the survivors sustain irreversible brain damage ${ }^{12}$. Known predictors for rupture include age, hypertension, history of SAH, aneurysm size and geographic location. Certain populations, like the Finns and Japanese, have considerably higher risks of rupture (3.6-fold and 2.8-fold, respectively) ${ }^{10}$ than other populations, and some genetic predispositions, such as polymorphisms on the SOX17 transcriptor regulation gene, endothelin receptor A gene, or cyclin-dependent kinase inhibitor genes, have been recently implicated in aneurysm formation ${ }^{13}$.

To date, the best evidence for risk of SAH from unruptured intracranial aneurysms is derived from the International Study of Unruptured Intracranial Aneurysms (ISUIA) ${ }^{14}$. Based on this and other studies ${ }^{2,5,9,15}$, the current recommendation is that asymptomatic patients harboring aneurysms smaller than $7 \mathrm{~mm}$ in diameter, without a previous history of rupture, should not receive treatment ${ }^{16,17}$. By contrast, other studies have suggested that aneurysms from the anterior communicating complex (ACoA), as well as those with large maximal diameter/neck diameter ratios, are more prone to bleed and must, therefore, be treated differently than that recommended by the guidelines ${ }^{18,19,20}$. Additionally, many retrospective series from large reference centers have reported a high proportion of small aneurysms among patients admitted with $\mathrm{SAH}^{3,21,22,23,24}$. More specifically, up to $88 \%$ of patients with SAH had aneurysms smaller than $10 \mathrm{~mm}$ in diameter at the time of the original diagnosis ${ }^{23}$. These data support the idea that the risk of bleeding associated with small aneurysms should not be underestimated. Several authors have tried to explain the discrepancy between the ISUIA results and large single-center experiences. We suggest an important variable in this discrepancy may be selection bias.

In the present study, we questioned the premise that small aneurysms do not carry a risk of rupture at the time of diagnosis. To this end, we retrospectively evaluated 290 patients referred to the University of Tübingen (Germany) over a six-year period. We propose a new method to address the relationship between aneurysm size and prevalence of rupture, based on logistic regression. Aneurysms were classified by size (small and large) based on the receiver operating characteristic (ROC) curve stratification instead of by arbitrarily defining size thresholds.

\section{METHODS}

For this study, we obtained clinical and radiological information for all patients diagnosed with intracranial aneurysms at the University of Tübingen, which included patient age, sex, tobacco dependence, comorbidities (e.g., diabetes mellitus, arterial hypertension or other vascular diseases), and location of aneurysm. Patients were excluded from the study if they had non-aneurysmal SAH. When patients had multiple aneurysms, ruptured intracranial aneurysms were identified by angiographic determinants or by direct observation during surgery.

Digital subtraction angiography and three-dimensional computed tomography angiography were used to evaluate the morphology of intracranial aneurysms. The following measurements were independently performed by two experienced neurosurgeons (C.A.F.L. and S.T.): 1) largest aneurysm diameter; 2) neck diameter; and 3) diameter of the nutrition vessel (Figure 1). Agreement between the two observers was quantified with the $\kappa$ test. For further calculations, we used the mean values from both observers.

Continuous data were expressed as means \pm standard errors. To assess data distribution, we applied the ShapiroWilk W test. Since all measured diameters obeyed normal distribution, mean comparisons were performed with Student's t-tests. To identify the independent parameters that had significant correlations with rupture, a multivariate logistic regression analysis was performed for all aneurysms (this is shown in a clustered color map). Categorical data were compared using a contingency analysis and Pearson's chi-square test. These data are shown graphically in mosaic plots. To address the relationship between size measurements and rupture at the time of diagnosis, we applied a logistic regression model and calculated the logistic probability of rupture. The resulting curve fit the model, and we present the curve, equation and curve coefficients. Additionally, we performed a ROC analysis to determine the optimal threshold value for each of the three measurements recorded (the area under the curve [AUC] reflects the goodness of the predictor). Based on this analysis, we calculated the sensitivity and specificity of the measures at the threshold. Finally, data were categorized into two groups (large and small values) according to the ROC analysis. We then compared the prevalence of rupture and other clinical features between groups.

For statistic computation and graphic representations, we used the JMP 11.1.1 software (SAS Institute Inc., NC, USA).

\section{RESULTS}

\section{Series characterization}

From January 2006 to December 2011, we collected clinical and radiological data from 290 consecutive and newlydiagnosed patients harboring intracranial aneurysms (346 aneurysms); $69 \%$ were female and $31 \%$ were male, with a mean age of $53.9 \pm 14.4$ years. Of the aneurysms, $43.7 \%$ were ruptured and $56.3 \%$ were unruptured. During this period, $30 \%$ of the patients were treated with endovascular procedures, 

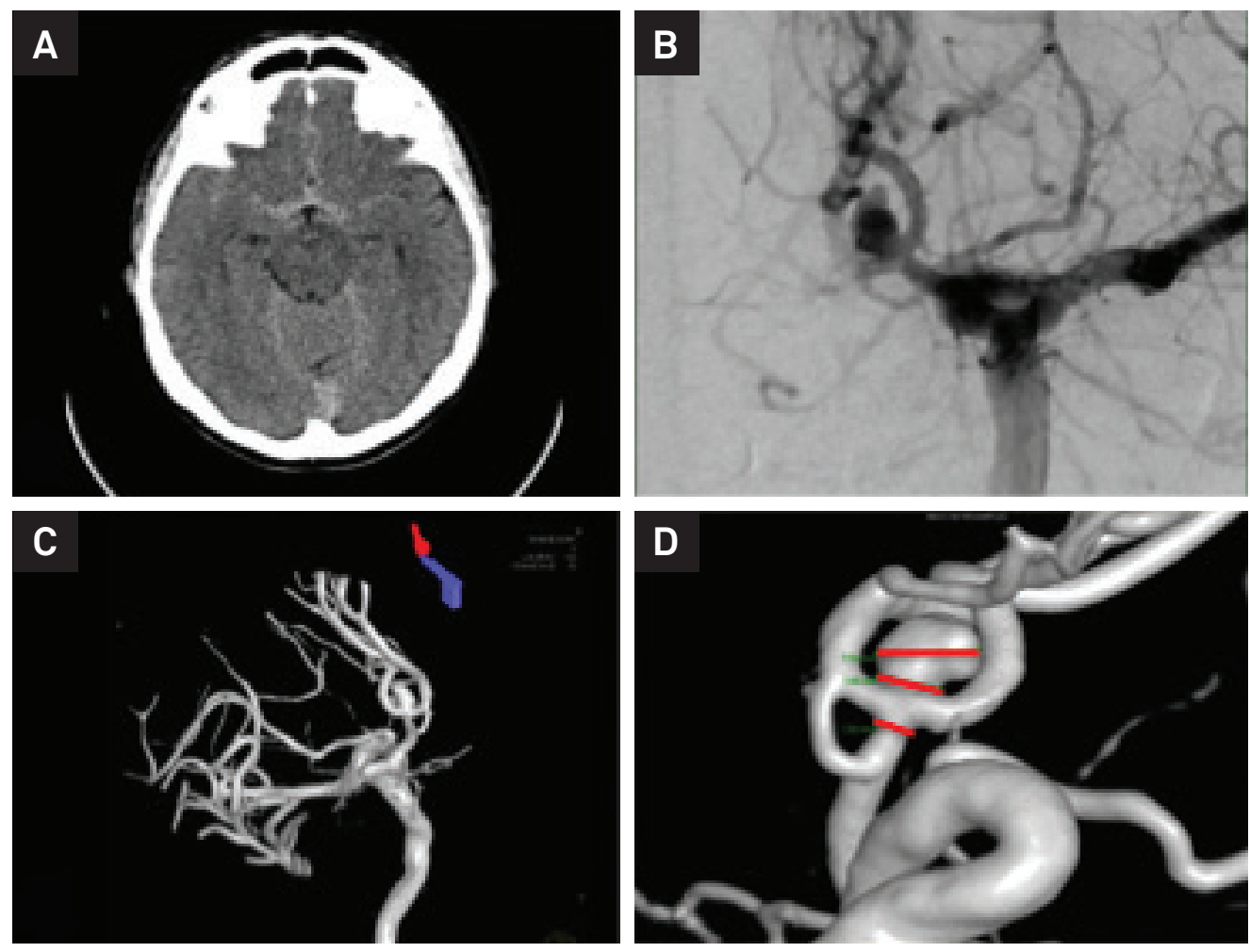

Figure 1. Illustrative case of a 42-year-old male patient who was admitted to our center on day 0 of a subarachnoid hemorrhage. A: CT-scan showing a Fisher 4 SAB grade with diffuse blood around the basal cisterns. B: digital subtraction angiography performed in emergency care, revealing a $6 \mathrm{~mm}$ anterior communicating complex aneurysm filled from the left internal carotid artery. C: three-dimensional reconstruction of the angio-CT scans. D: example of the measurements performed of the maximal aneurysm diameter, neck diameter, and diameter of the nutrition vessel.

while $70 \%$ were treated surgically. Arterial hypertension was the most frequent comorbidity encountered (26.3\%), and tobacco dependence the second (6.2\%). Forty-two patients out of 290 presented with more than one aneurysm. The most frequent localization was the middle cerebral artery (35.7\%), followed by anterior cerebral artery/anterior communicating artery complex (ACA/ACoA, [33.4\%]), then the internal carotid artery (including the communicating posterior segment, 18.3\%), and finally, the vertebrobasilar system (11.1\%). In total, $21.8 \%$ of the aneurysms in this series measured less than $5 \mathrm{~mm}$ in maximal diameter, $23.4 \%$ measured between $5-7 \mathrm{~mm}, 14.7 \%$ between $7-10 \mathrm{~mm}$, and $34.4 \%$ were larger than $10 \mathrm{~mm}$.

\section{Clinical factors associated with rupture}

The multivariate analysis (Figure 2A) revealed a positive correlation between arterial hypertension and rupture (Pearson's $r=0.2276, p<0.001$ ), tobacco dependence and hypertension $(r=0.1576, p<0.01)$, other cardiovascular diseases and hypertension $(r=0.2061, p<0.001)$, age and arterial hypertension $(r=0.2824, p<0.001)$. We also show in Figure $2 \mathrm{~B}$ and Figure $2 \mathrm{C}$ a contingency analysis for aneurysm localization and arterial hypertension versus chance of rupture. Aneurysms of the anterior cerebral artery and patients with arterial hypertension were at higher risk of bleeding $(\mathrm{p}<0.05$ and $<0.001$, respectively).
In the ruptured group, $42.6 \%$ of aneurysms occurred in the ACA/ACoA, $16.3 \%$ in the internal carotid artery, $31.8 \%$ in the middle cerebral artery, and $9.3 \%$ in the vertebrobasilar system. In the unruptured group, these rates were $27.3 \%$ in the ACA/ACoA, $22.7 \%$ in the internal carotid artery, $36.9 \%$ in the middle cerebral artery, and $13.1 \%$ in the vertebrobasilar system. Therefore, there was a higher proportion of ACA/ACoA aneurysms in the ruptured group ( $\mathrm{p}<0.05$, Pearson's chi-square).

Pairwise analysis revealed that the chance of rupture at the time of the original diagnosis was significantly higher for patients with a previous diagnosis of hypertension (Pearson's chi-square $\mathrm{p}<0.001)$ and for aneurysms located in the ACA/ACoA complex (Pearson's chi-square $\mathrm{p}<0.05$ ). In the present series, we did not observe any relationship between rupture and diabetes mellitus, tobacco dependence, age, sex, or cardiovascular diseases other than hypertension.

\section{Angiographic size measurements and rupture}

All three angiographic parameters analyzed were inversely correlated with rupture, and strongly correlated with each other (largest diameter, $\mathrm{r}=-0.1576, \mathrm{p}<0.001$, neck diameter, $\mathrm{r}=-0.1775, \mathrm{p}<0.001$, and diameter of the nutrition vessel, $r=-0.1725, p<0.001$; Figure 2A). Moreover, all measurements were strongly associated with each other (largest $\mathrm{x}$ neck: $\mathrm{r}=0.8375$, largest $\mathrm{x}$ nutrition: $\mathrm{r}=0.8113$, neck $\mathrm{x}$ nutrition: $\mathrm{r}=0.7747$; all $\mathrm{p}<0.001$ ). 
A

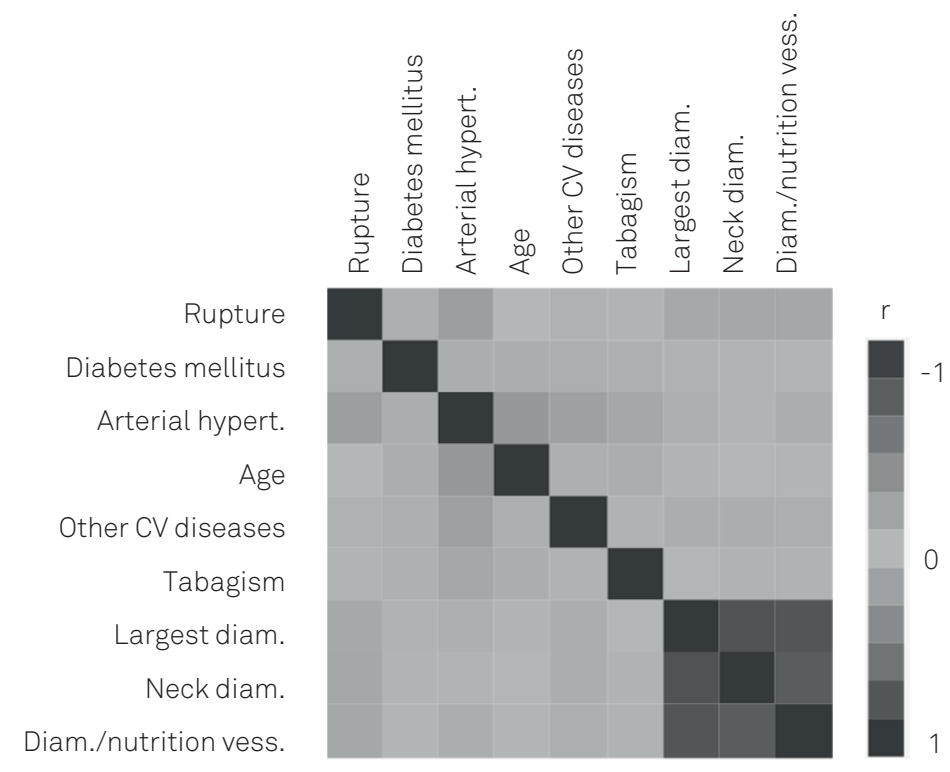

B

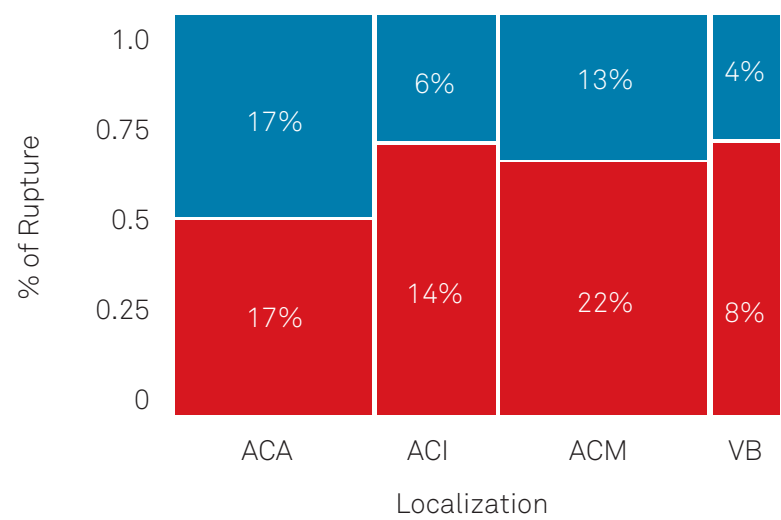

C

Figure 2. A: mosaic plot of the multivariate analysis, with Pearson's correlation coefficients represented in a colored map (scale on the right). Note that rupture (first line) is positively correlated with arterial hypertension $(r=0.2276$, $p<0.001)$ but negatively correlated with the largest aneurysm diameter $(r=-0.1576, p<0.001)$, neck diameter $(r=-0.1775, p<0.001)$ and diameter of the nutrition vessel $(r=-0.1725, p<0.001)$. Moreover, all diameters measured have a strong direct linear relationship among each other (largest $x$ neck: $r=0.8375$, largest $x$ nutrition: $r=0.8113$, and neck x nutrition: $r=0.7747$; all $p<0.001$ ). In B and C, contingency analysis with mosaic plots for aneurysm localization versus chance of rupture (B), and arterial hypertension versus chance of rupture (C).

\section{Rupture at the time of diagnosis, according to the logistic regression model}

To evaluate the influence of each angiographic size parameter on the chance of rupture at the time of the original diagnosis, we applied logistic regression. According to our model, the chance of rupture $(r=1)$ obeys the following equation (1):

$$
{ }_{\mathrm{pLD}}(\mathrm{r}=1)=1-\left(1 / 1+\mathrm{e}^{\left(-0.1628-0.0154^{*} \mathrm{LD}\right)}\right)(1)
$$

Where $\mathrm{p}_{\mathrm{LD}}$ refers to the chance of rupture as a function of the largest aneurysm diameter (LD is the largest diameter). The curve coefficients were $-0.1628 \pm 0.1431$ and 0.0154 \pm 0.0057 (whole model test, $p<0.05$ ). As can be seen in Figure $3 \mathrm{~B}$, the bigger the largest diameter, the greater the chance of rupture at the time of diagnosis.

Similarly, we also found a negative association between aneurysm neck diameter and chance of rupture.
Accordingly, the chance of rupture is described by the following equation (2):

$$
{ }_{\mathrm{pND}}(\mathrm{r}=1)=1-\left(1 / 1+\mathrm{e}^{\left(-0.1082-0.0354^{*} \mathrm{ND}\right)}\right)(2)
$$

Where $\mathrm{p}_{\mathrm{ND}}$ refers to the chance of rupture as a function of the aneurysm neck diameter (ND is the neck diameter). The curve coefficients were $-0.1082 \pm 0.1501$ and $0.0354 \pm 0.0121$ (whole model test, $\mathrm{p}<0.001$ ) (Figure 3D).

Finally, we also examined the chance of rupture as a function of the diameter of the nutrition vessel, which yielded the following equation (3):

$$
{ }_{\mathrm{pDNV}}(\mathrm{r}=1)=1-\left(1 / 1+\mathrm{e}^{(-01329-0.0480 \text { " DNV })}\right)(3)
$$

Where $\mathrm{p}_{\mathrm{DNV}}$ refers to the chance of rupture as a function of the diameter of the nutrition vessel (DNV is the diameter of the nutrition vessel). The curve coefficients were $-0.1329 \pm 0.1460$ and $0.0480 \pm 0.0160$ (whole model test, $\mathrm{p}<0.01$ ) (Figure 3F). 
A

Logistic prob.
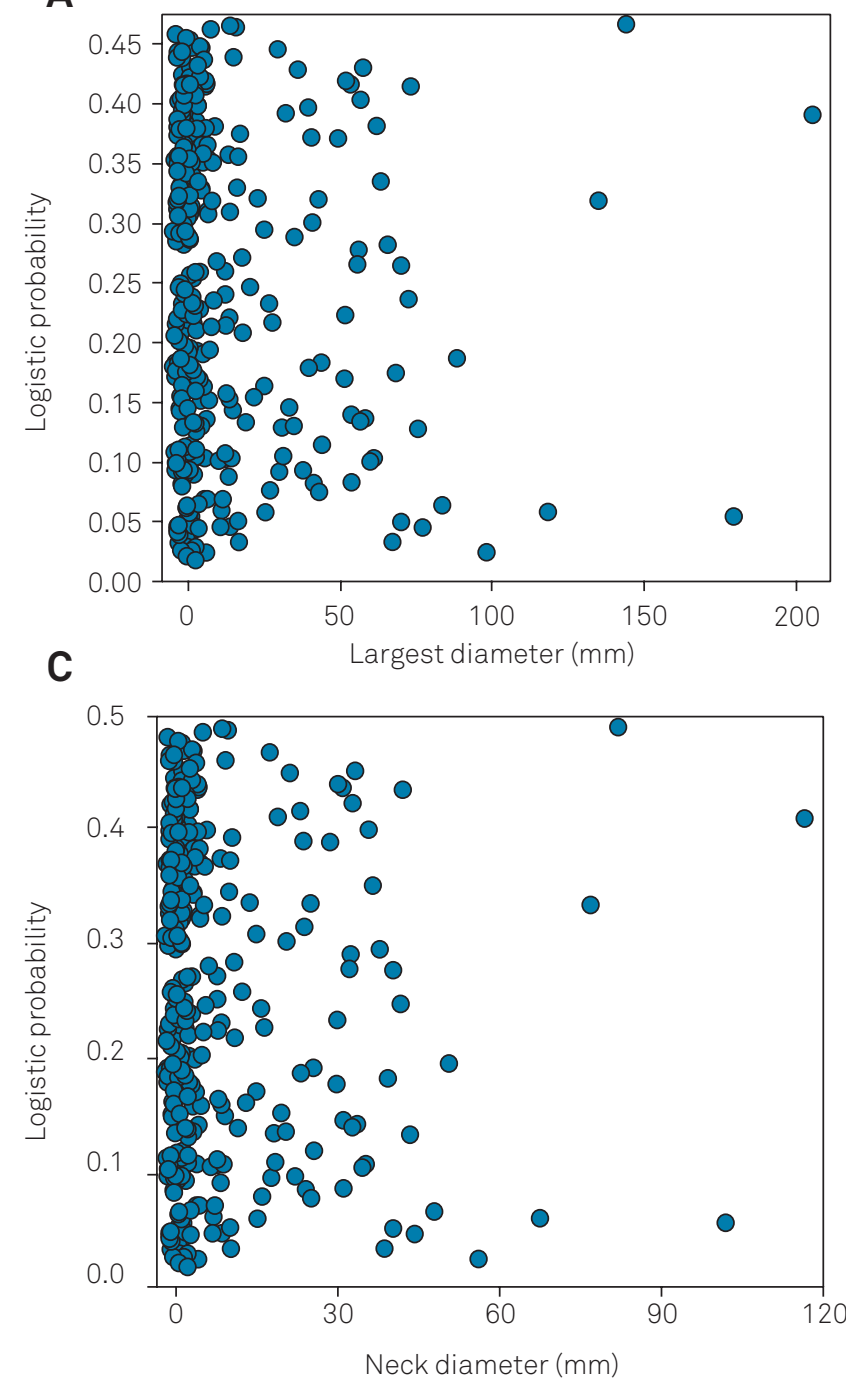

E

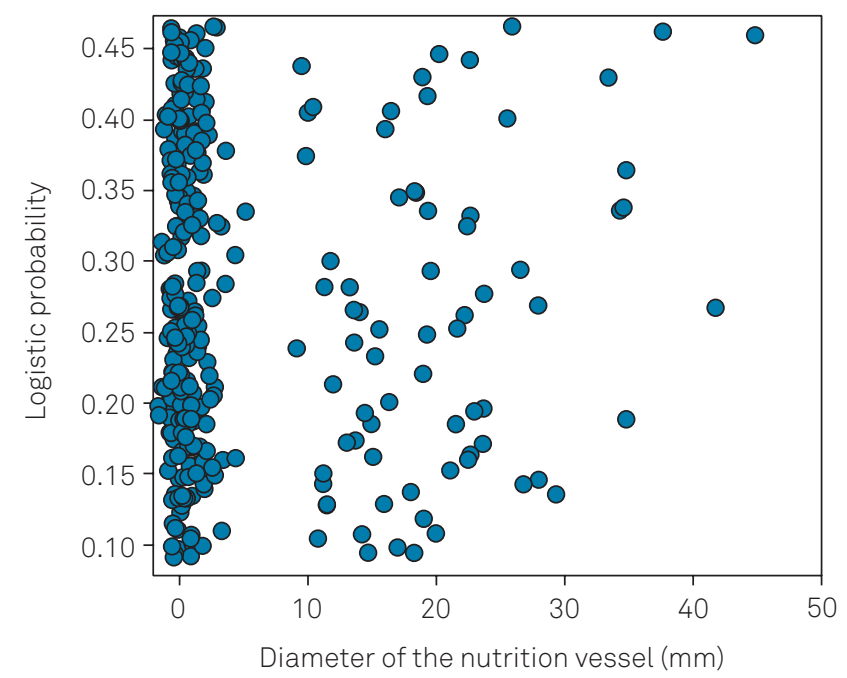

B

Mean probability of rupture

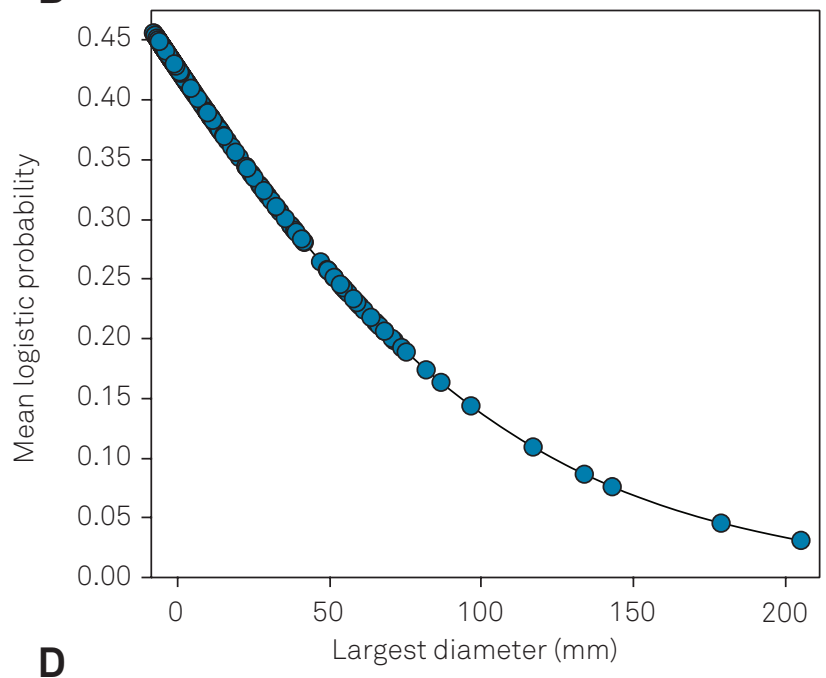

D

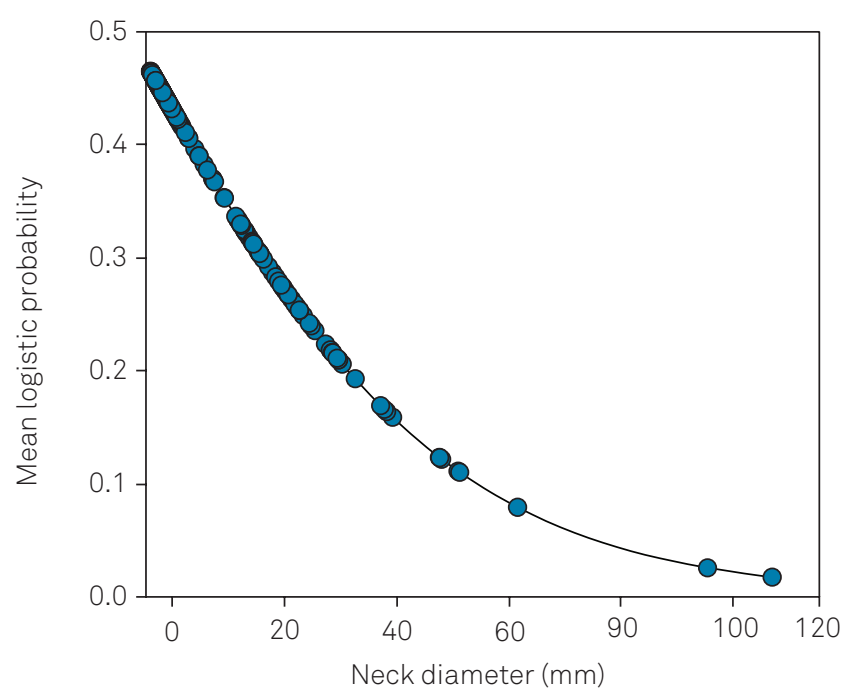

$\mathbf{F}$

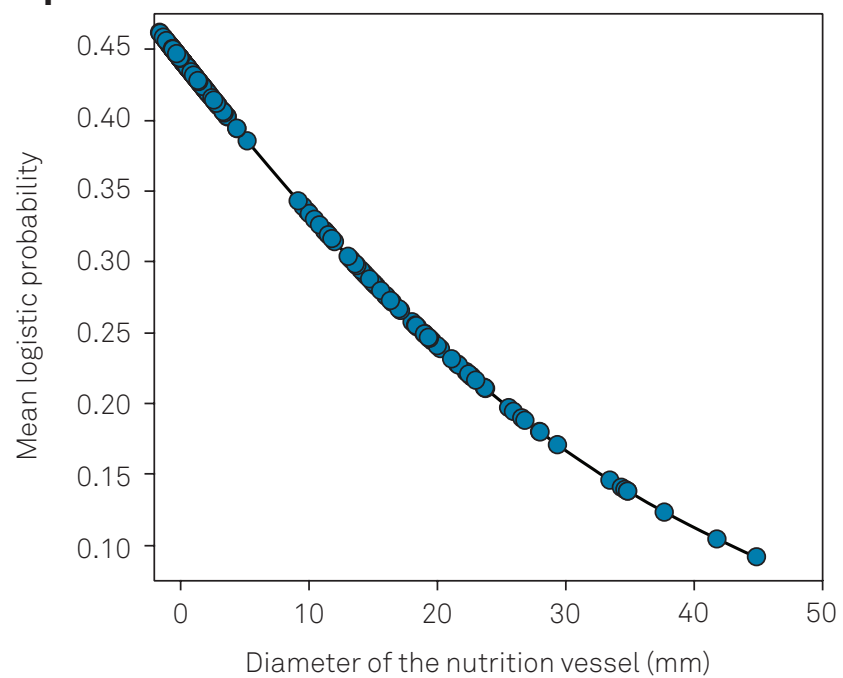

Figure 3. Logistic regression model used to predict chance of bleeding by the time of admission. On the left side, logistic probability plots of the largest aneurysm diameter (A), neck diameter (C), and diameter of the nutrition vessel (E). Each plot represents one patient. On the right side (B,D,F), mean logistic probability as a function of diameter, calculated based on the graphs on the left. The curve fittings indicate a logarithmic decay of the probability of bleeding as a function of diameter. For the largest aneurysm diameter (LD), the probability of rupture $(r=1)$ was described by the equation $p L D(r=1)=1-\left(1 /\left(1+e^{\wedge}((-0.1628-\right.\right.$ $\left.\left.\left.\left.0.0154^{*} \mathrm{LD}\right)\right)\right)\right)$. Similarly, for neck diameter, the deduced equation was pND $(r=1)=1-\left(1 /\left(1+\mathrm{e}^{\wedge}\left(\left(-0.1082-0.0354^{\star} \mathrm{ND}\right)\right)\right)\right.$, and for diameter of the nutrition vessel, pDNV $(r=1)=1-\left(1 /\left(1+e^{\wedge}((-0.1329-0.0480 * D N V))\right)\right.$. All curves indicate that the larger the aneurysm, the higher the probability of rupture at the time of admission. 
On the left side of Figure 3 we demonstrate logistic probability plots of the largest aneurysm diameter (Figure 3A), neck diameter (Figure 3C), and diameter of the nutrition vessel (Figure 3E).

\section{Sample stratification according to size}

In order to address the chance of rupture in the study population, we stratified the sample into two groups: large and small diameter aneurysms. Differently from what has previously been published, the threshold value used for this measurement was based on the ROC analysis using rupture as the outcome variable (Figure 4). First, the AUCs show how well the variables predict rupture. For large diameter, the AUC was 0.5812, for neck diameter, $\mathrm{AUC}=0.6150$, and for diameter of the nutrition vessel, $\mathrm{AUC}=0.5881$. Since all values were less than 0.7 , we concluded that size was not a good predictor of bleeding in this population. The threshold value for the largest diameter was $14.97 \mathrm{~mm}$; at this value, the sensitivity to predict rupture was $82.95 \%$ and the specificity was $35.53 \%$. For the neck diameter, the threshold was

ROC curves
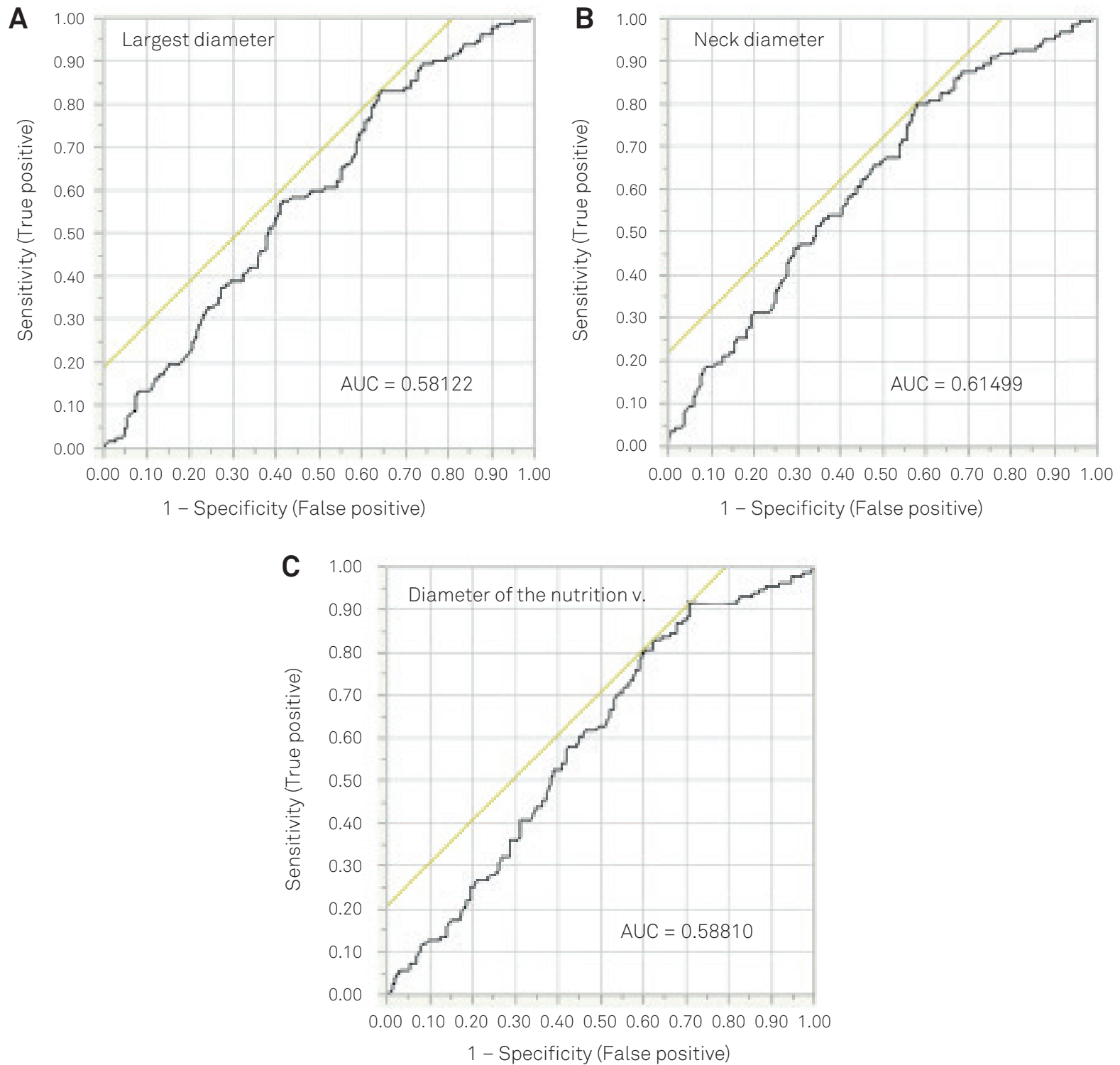

Figure 4. Receiver operating characteristic (ROC) analysis for largest diameter (A), neck diameter (B) and diameter of the nutrition vessel (C). The area under the curve indicates how well the variable predicts rupture. Since all values were lower than 0.7, we deduced that aneurysm size was, in fact, not a strong predictor of rupture. From the ROC tables, we calculated the values of the three diameter variables that were associated with the highest sensitivity and specificity. For the variable "largest diameter", the cut-off point was $14.97 \mathrm{~mm}$; at this value, we found a sensitivity of $82.95 \%$ and specificity of $35.53 \%$ for rupture prediction. Similarly, the cut-off value for the neck diameter was $4.72 \mathrm{~mm}$, with a sensitivity of $79.83 \%$ and a specificity of $41.9 \%$. Finally, for the diameter of the nutrition vessel, the cut-off was $12.04 \mathrm{~mm}$, which was associated with a sensitivity of $91.41 \%$ and specificity of $28.93 \%$. The ROC analysis allows a more precise definition of representative groups within the sample population. 
A

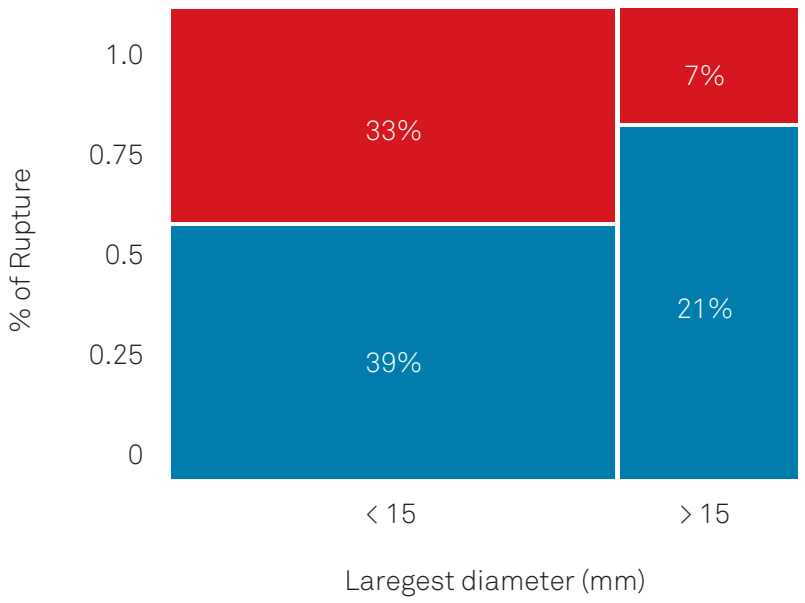

C

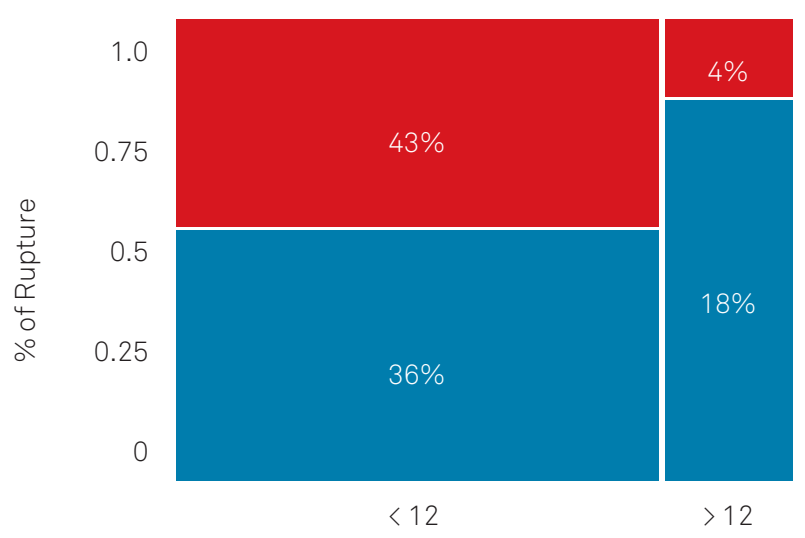

Diameter of the nutrition vessel $(\mathrm{mm})$

\section{B}

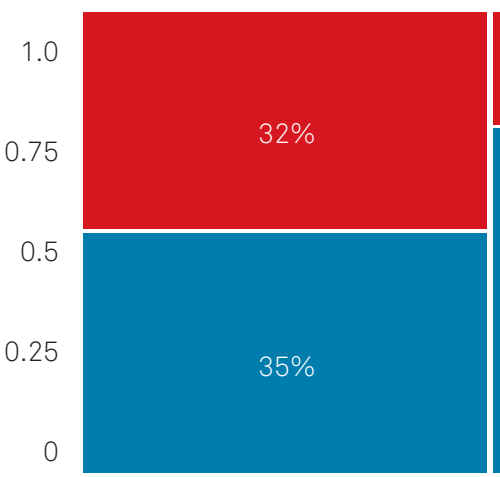

$<5$

Neck diameter $(\mathrm{mm})$

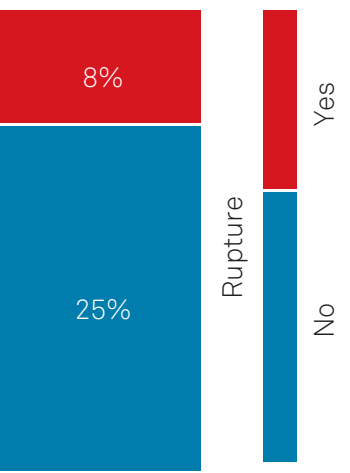

$>5$
D

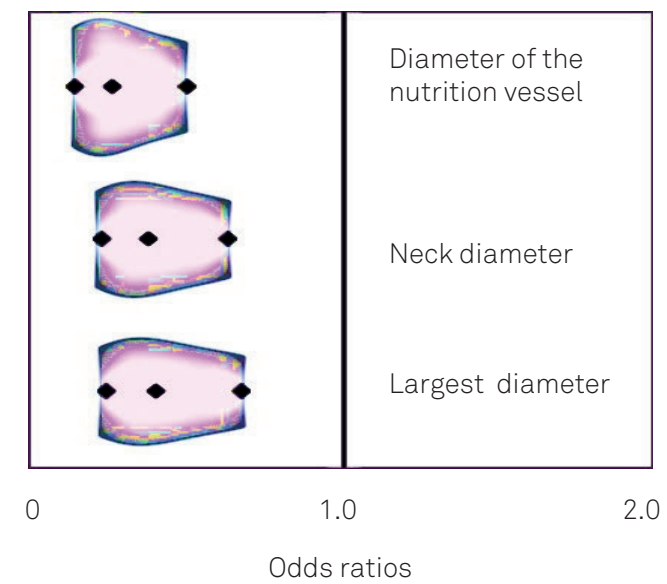

Figure 5. Contingency analysis for probability of rupture in two groups of patients (small and large aneurysms), which were defined based on the ROC analysis (Figure 4). In A, note a higher probability of rupture at the time of admission for patients harboring small aneurysms (large diameter less than $15 \mathrm{~mm}$ ). For small aneurysms, the probability of rupture was $45.5 \%$, which dropped to $24.7 \%$ if the aneurysm was larger than $15 \mathrm{~mm}$ in its maximal diameter (Pearson's chi-square p $<0.001$ ). In B, a similar analysis was conducted for neck diameter; here, the probability of rupture was $47.5 \%$ for narrower necks $(<5 \mathrm{~mm})$ and $25.0 \%$ for wider necks (Pearson's chi-square $\mathrm{p}<0.001)$. Finally, in C (nutrition vessel), the smaller nutrition $(<12 \mathrm{~mm})$ was associated with $45.3 \%$ probability of rupture at the time of admission, which was much higher than the probability of $17.4 \%$ observed for patients with larger nutrition vessels (Pearson's chi-square $p<0.001)$. Next, we calculated the odds ratio for rupture in relation to each of the measurements. For largest diameter, $\mathrm{OR}=0.3937(95 \% \mathrm{Cl}=0.2301$ to 0.6735$)$, for neck diameter, OR $=0.3688$ $(95 \% \mathrm{Cl}=0.2167$ to 0.6276$)$, and for diameter of the nutrition vessel, $\mathrm{OR}=0.2541(95 \% \mathrm{Cl}=0.1301$ to 0.4962$)$. Odds ratios below 1 indicate that, in our series, large sizes were in fact protective against rupture.

$4.72 \mathrm{~mm}$, with a sensitivity of $79.83 \%$ and a specificity of $41.90 \%$. Finally, for the diameter of the nutrition vessel, the threshold was $12.04 \mathrm{~mm}$, with a sensitivity of $91.41 \%$ and a specificity of $28.93 \%$.

Based on this analysis, we divided the sample into aneurysms with largest diameter $>$ and $\leq 15 \mathrm{~mm}$, neck diameter $>$ and $\leq 5 \mathrm{~mm}$, and diameter of the nutrition vessel $>$ and $\leq 12 \mathrm{~mm}$ (Figure 5). We observed that the chance of rupture at the time of diagnosis was $45.5 \%$ if the aneurysm was larger than $15 \mathrm{~mm}$ at its largest diameter and only $24.7 \%$ if it was less than or equal to $15 \mathrm{~mm}$ ( $\mathrm{p}<0.001$, odds ratio $[\mathrm{OR}]=0.3937,95 \% \mathrm{CI}=0.2301$ to 0.6735$)$. Similarly, the chance was $47.5 \%$ for aneurysms with necks smaller than $5 \mathrm{~mm}$ and $25.0 \%$ if the neck was larger than $5 \mathrm{~mm}(\mathrm{p}<0.001, \mathrm{OR}=0.3688$, $95 \% \mathrm{CI}=0.2167$ to 0.6276 ), and $45.3 \%$ for aneurysms whose nutrition vessel was smaller than $12 \mathrm{~mm}$ and only $17.4 \%$ for aneurysms whose nutrition vessel was larger than $12 \mathrm{~mm}$ $(\mathrm{p}<0.001, \mathrm{OR}=0.2541,95 \% \mathrm{CI}=0.1301$ to 0.4962$)$.

\section{DISCUSSION}

The prevalence of intracranial aneurysms is relatively high (2-6\%, depending on the diagnostic method used $)^{9}$. 
Furthermore, SAH is a potentially fatal condition, with a reported mortality rate of $52 \%^{16}$ to $83 \%^{15}$.

The retrospective arm of the ISUIA reported that the risk of rupture of an aneurysm smaller than $10 \mathrm{~mm}$ in a patient with no previous SAH was only $0.05 \%$. Compared with other studies $^{6,15}$, the reported risk of rupture was 10 to 12 times lower than previously estimated. Based on this, the recommendation was to manage aneurysms measuring less than $10 \mathrm{~mm}$ expectantly. Later, detailed analyses of that study suggested that it may have suffered from methodological issues, such as selection bias $^{25}$.

In the ISUIA Part $2^{2}$, higher rupture rates for small aneurysms were reported. Nevertheless, the major concerns regarding selection criteria remain. The annual rupture rates for aneurysms $7 \mathrm{~mm}$ to $12 \mathrm{~mm}$ in size were $0.5 \%$ in the anterior circulation and $2.9 \%$ in the posterior circulation. It is important to note that, in that study, aneurysms arising from the posterior communicating segment of the carotid were grouped under "posterior circulation". This might have contributed to the increased rupture risk in this group.

Based on the above report, mathematical algorithms have been developed to help the decision-making process regarding treatment necessity ${ }^{26,27,28}$. According to Mitchell and Jakubowski ${ }^{26}$, intervention in patients with aneurysms smaller than $10 \mathrm{~mm}$ with no SAH was not justified (assumption based on lost life-years in the risk calculation). These authors concluded that intervention in unruptured aneurysms was justified only for patients up to 50 years of age (see also Vindlacheruvu et al. ${ }^{27}$ ). According to Yoshimoto ${ }^{28}$, mathematical risk models suggest that prophylactic treatment of unruptured aneurysms may produce some benefit for large aneurysms. Moreover, given the low treatment-related morbidity-mortality in young populations harboring small aneurysms, intervention might be justified in this group ${ }^{28}$.

Further analysis of the available data on unruptured aneurysms culminated with the following recommendations made by the Stroke Council of the American Heart Association ${ }^{16}$ : 1) Asymptomatic intracavernous aneurysms should not be treated. In large symptomatic ones, the treatment should be individualized. 2) All symptomatic intradural aneurysms should be treated. 3) Incidental aneurysms with a diameter less than $10 \mathrm{~mm}$ should not be treated. Nevertheless, lesions approaching $10 \mathrm{~mm}$, those with daughter aneurysm formation, those in young patients or in individuals with a family history of SAH, deserve special consideration for treatment. 4) Aneurysms found in association with a ruptured lesion and those with a diameter greater than $10 \mathrm{~mm}$ deserve strong consideration for treatment, especially in young patients.

The fact that rupture occurs preferentially in small aneurysms has been reported by numerous authors ${ }^{5,6,21,22,23,24,29}$. In the United States, it was reported that $80 \%$ of the 28,000 aneurysmal SAHs occurred in lesions smaller than $10 \mathrm{~mm}$, indicating a $0.72 \%$ to $1.36 \%$ annual rupture rate for this group $^{30}$. Inagawa ${ }^{20}$ reported $24 \%$ rupture in aneurysms smaller than $5 \mathrm{~mm}$, $48 \%$ for aneurysms measuring between $5 \mathrm{~mm}$ and $10 \mathrm{~mm}$, and only $28 \%$ for those larger than $10 \mathrm{~mm}$ from a sample of 285 patients studied. Lai et al. ${ }^{31}$ observed even more drastic numbers: according to their experience, SAH originating from aneurysms smaller than $5 \mathrm{~mm}$ occurred in $68 \%$ of patients $(\mathrm{n}=267)$. Joo et al..$^{22}$ observed that $71.8 \%$ of their 627 cases of ruptured aneurysms presented with lesions smaller than $7 \mathrm{~mm}$ in diameter, and $87.9 \%$ were smaller than $10 \mathrm{~mm}$. The high mortality rate in cases of rupture ${ }^{8}$ highlights the importance of carefully deciding whether to treat patients harboring small aneurysms.

To explain the discrepancy between the reported reduced risk of rupture in small aneurysms and the higher prevalence of small aneurysms among those that rupture, one hypothesis suggests that aneurysms shrink after bleeding ${ }^{21}$. However, this hypothesis is not widely accepted, and some authors believe that aneurysms may even grow before rupturing ${ }^{32,33}$. Another hypothesis is that there seems to be a high-risk period soon after aneurysm formation, which is followed by a period of risk stabilization ${ }^{26}$.

Although these phenomena may partially explain the controversy, we cannot ignore the possibility that methodological issues may have played an important role in the results reported in the ISUIA studies ${ }^{34,35}$. Selection bias has been pointed out as a major drawback in the ISUIA studies, with preferential treatment and exclusion of patients who were symptomatic, or who had aneurysms with certain morphological characteristics (e.g., daughter sacs or irregular borders), and those with a family history of $\mathrm{SAH}^{1,4,5,8}$.

The study by Juvela et al. ${ }^{5}$, though observational, provides first line evidence about the natural history of unruptured intracranial aneurysms. Aneurysm size and patient age were significant predictors of aneurysmal SAH, as was active cigarette smoking (all $\mathrm{p}<0.05$ ). Rinkel et al. ${ }^{9}$ published a meta-analysis about the natural history of unruptured intracranial aneurysms. Among nine studies including a total of 3,907 patients, the overall risk of rupture was $1.9 \%$ per year $(0.7 \%$ for unruptured aneurysms $<10 \mathrm{~mm}$ and $4 \%$ for intact lesions $>10 \mathrm{~mm}$ ). According to Dickey et al. ${ }^{36}$, the fact that the ISUIA and other studies mostly involved investigators from busy neurovascular centers, who routinely treated patients with larger aneurysms, created the false impression that the smaller aneurysms in their practice had a lower rupture rate ${ }^{36}$.

Because rupture risk reflects a biological problem, it is unlikely that risk distribution changes abruptly beyond a certain threshold of aneurysm size. Supporting this idea, Dickey and Kailasnath ${ }^{36}$ reported the "diameter-cube hypothesis," a mathematical model that describes the rupture potential of any given aneurysm as continuously increasing on the basis of the maximum diameter of the aneurysm cubed. Here, we propose a different way to calculate risk in a sample population, based on logistic regression. Our model predicts that 
risk decreases logarithmically as a function of size. The low $\mathrm{p}$ values observed for the whole model-test support its robustness. Moreover, it has been proposed that the diameter of the nutrition vessel, or the neck diameter, either individually or in relation to the maximal diameter (size ratio), represent more reliable predictors of rupture ${ }^{18,19,33}$.

Additionally, the ROC analysis revealed that these measurements have similar predictive power for ruptures (see AUCs). However, none of the parameters proved to be strong predictors in the present sample (AUC < 0.7). Notably, size stratification in this study was performed according to the ROC analysis, and large aneurysms with a reduced risk of bleeding (such as intracavernous, or those with calcified walls) were not excluded from the analysis. Exclusion would have generated higher risk values for large aneurysms but would have created selection bias, rendering the risk calculation inexact.

In conclusion, we have presented a mathematical model to describe the chance of aneurysm rupture at the time of diagnosis, based on logarithmic regression. Our model predicts a logarithmic decay of the chance of rupture as a function of aneurysm diameter. Size stratification according to the ROC analysis revealed that, at least for the population referred to our center in southern Germany, small aneurysms are especially worrisome. It remains to be determined whether this statement is also applicable to other populations.

\section{References}

1. Morita A, Kirino T, Hashi K, Aoki N, Fukuhara S, Hashimoto N, et al.; UCAS Japan Investigators. The natural course of unruptured cerebral aneurysms in a Japanese cohort. N Engl J Med. 2012 Jun;366(26):2474-82. https://doi.org/10.1056/NEJMoa1113260

2. Wiebers DO, Whisnant JP, Huston J 3rd, Meissner I, Brown RD Jr, Piepgras DG, et al.; International Study of Unruptured Intracranial Aneurysms Investigators. Unruptured intracranial aneurysms: natural history, clinical outcome, and risks of surgical and endovascular treatment. Lancet. 2003 Jul;362(9378):103-10. https://doi.org/10.1016/S0140-6736(03)13860-3

3. Beck J, Rohde S, Berkefeld J, Seifert V, Raabe A. Size and location of ruptured and unruptured intracranial aneurysms measured by 3-dimensional rotational angiography. Surg Neurol. 2006 Jan;65(1):18-25. https://doi.org/10.1016/j.surneu.2005.05.019

4. Forget TR Jr, Benitez R, Veznedaroglu E, Sharan A, Mitchell W, Silva M, et al. A review of size and location of ruptured intracranial aneurysms. Neurosurgery. 2001 Dec;49(6):1322-5. https://doi.org/10.1097/00006123-200112000-00006

5. Juvela S, Porras M, Heiskanen O. Natural history of unruptured intracranial aneurysms: a long-term follow-up study. J Neurosurg. 1993 Aug;79(2):174-82. https://doi.org/10.3171/jns.1993.79.2.0174

6. Juvela S, Porras M, Poussa K. Natural history of unruptured intracranial aneurysms: probability of and risk factors for aneurysm rupture. J Neurosurg. 2008 May;108(5):1052-60. https://doi.org/10.3171/JNS/2008/108/5/1052

7. Ohashi Y, Horikoshi T, Sugita M, Yagishita T, Nukui H. Size of cerebral aneurysms and related factors in patients with subarachnoid hemorrhage. Surg Neurol. 2004 Mar;61(3):239-45. https://doi.org/10.1016/S0090-3019(03)00427-0

8. Sonobe M, Yamazaki T, Yonekura M, Kikuchi H. Small unruptured intracranial aneurysm verification study: SUAVe study, Japan. Stroke. 2010 Sep;41(9):1969-77. https://doi.org/10.1161/STROKEAHA.110.585059

9. Rinkel GJ, Djibuti M, Algra A, Gijn J. Prevalence and risk of rupture of intracranial aneurysms: a systematic review. Stroke. 1998 Jan;29(1):251-6. https://doi.org/10.1161/01.STR.29.1.251

10. Greving JP, Wermer MJ, Brown RD Jr, Morita A, Juvela S, Yonekura $\mathrm{M}$, et al. Development of the PHASES score for prediction of risk of rupture of intracranial aneurysms: a pooled analysis of six prospective cohort studies. Lancet Neurol. 2014 Jan;13(1):59-66. https://doi.org/10.1016/S1474-4422(13)70263-1

11. Etminan N, Buchholz BA, Dreier R, Bruckner P, Torner JC, Steiger $\mathrm{HJ}$, et al. Cerebral aneurysms: formation, progression, and developmental chronology. Transl Stroke Res. 2014 Apr;5(2):167-73. https://doi.org/10.1007/s12975-013-0294-x

12. Graves EJ. Detailed diagnoses and procedures, national hospital discharge survey, 1990. Vital Health Star 13. 1992 Jun;113:1-25.

13. Alg VS, Sofat R, Houlden H, Werring DJ. Genetic risk factors for intracranial aneurysms: a meta-analysis in more than 116,000 individuals. Neurology. 2013 Jun;80(23):2154-65. https://doi.org/10.1212/WNL.0b013e318295d751

14. International Study of Unruptured Intracranial Aneurysms Investigators. Unruptured intracranial aneurysms - risk of rupture and risks of surgical intervention. International study of unruptured intracranial aneurysms investigators. N Engl J Med. 1998;339(24):1725-33. https://doi.org/10.1056/NEJM199812103392401

15. Tsutsumi K, Ueki K, Morita A, Kirino T. Risk of rupture from incidental cerebral aneurysms. J Neurosurg. 2000 Oct;93(4):550-3. https://doi.org/10.3171/jns.2000.93.4.0550

16. Bederson JB, Awad IA, Wiebers DO, Piepgras D, Haley EC $\mathrm{Jr}$, Brott T, et al. Recommendations for the management of patients with unruptured intracranial aneurysms: a statement for healthcare professionals from the Stroke Council of the American Heart Association. Stroke. 2000 Nov;31(11):2742-50. https://doi.org/10.1161/01.STR.31.11.2742

17. Komotar RJ, Mocco J, Solomon RA. Guidelines for the surgical treatment of unruptured intracranial aneurysms: the first annual J. Lawrence pool memorial research symposium - controversies in the management of cerebral aneurysms. Neurosurgery. 2008 Jan;62(1):183-93. https://doi.org/10.1227/01.NEU.0000311076.64109.2E

18. Dhar S, Tremmel M, Mocco J, Kim M, Yamamoto J, Siddiqui AH, et al. Morphology parameters for intracranial aneurysm rupture risk assessment. Neurosurgery. 2008 Aug;63(2):185-96. https://doi.org/10.1227/01.NEU.0000316847.64140.81

19. Kashiwazaki D, Kuroda S. Size ratio can highly predict rupture risk in intracranial small ( $<5 \mathrm{~mm})$ aneurysms. Stroke. 2013 Aug;44(8):2169-73. https://doi.org/10.1161/STROKEAHA.113.001138

20. Ma D, Tremmel M, Paluch RA, Levy El, Meng H, Mocco $\mathrm{J}$. Size ratio for clinical assessment of intracranial aneurysm rupture risk. Neurol Res. 2010 Jun;32(5):482-6. https://doi.org/10.1179/016164109X12581096796558

21. Inagawa T. Size of ruptured intracranial saccular aneurysms in patients in Izumo City, Japan. World Neurosurg. 2010 Feb;73(2):84-92. https://doi.org/10.1016/j.surneu.2009.07.001 
22. Joo SW, Lee SI, Noh SJ, Jeong YG, Kim MS, Jeong YT. What is the significance of a large number of ruptured aneurysms smaller than $7 \mathrm{~mm}$ in diameter? J Korean Neurosurg Soc. 2009 Feb;45(2):85-9.

https://doi.org/10.3340/jkns.2009.45.2.85

23. Juvela S. Natural history of unruptured intracranial aneurysms: risks for aneurysm formation, growth, and rupture. Acta Neurochir Suppl (Wien). 2002;82:27-30. https://doi.org/10.1007/978-3-7091-6736-6_5

24. Weir B, Disney L, Karrison T. Sizes of ruptured and unruptured aneurysms in relation to their sites and the ages of patients. J Neurosurg. 2002 Jan;96(1):64-70. https://doi.org/10.3171/jns.2002.96.1.0064

25. Chen PR, Frerichs K, Spetzler R. Natural history and general management of unruptured intracranial aneurysms. Neurosurg Focus. 2004 Nov;17(5):E1. https://doi.org/10.3171/foc.2004.17.5.1

26. Mitchell P, Jakubowski J. Estimate of the maximum time interval between formation of cerebral aneurysm and rupture.J Neurol Neurosurg Psychiatry. 2000 Dec;69(6):760-7. https://doi.org/10.1136/jnnp.69.6.760

27. Vindlacheruvu RR, Mendelow AD, Mitchell P. Risk-benefit analysis of the treatment of unruptured intracranial aneurysms. J Neurol Neurosurg Psychiatry. 2005 Feb;76(2):234-9. https://doi.org/10.1136/jnnp.2003.031930

28. Yoshimoto Y.A mathematical model of the natural history of intracranial aneurysms: quantification of the benefit of prophylactic treatment. J Neurosurg. 2006 Feb;104(2):195-200. https://doi.org/10.3171/jns.2006.104.2.195

29. Qureshi Al, Sung GY, Suri MF, Straw RN, Guterman LR, Hopkins LN. Factors associated with aneurysm size in patients with subarachnoid hemorrhage: effect of smoking and aneurysm location. Neurosurgery. 2000 Jan;46(1):44-50. https://doi.org/10.1093/neurosurgery/46.1.44
30. Phillips LH 2nd, Whisnant JP, O'Fallon WM, Sundt TM Jr. The unchanging pattern of subarachnoid hemorrhage in a community. Neurology. 1980 Oct;30(10):1034-40. https://doi.org/10.1212/WNL.30.10.1034

31. Lai HP, Cheng KM, Yu SC, Au Yeung KM, Cheung YL, Chan CM, et al. Size, location, and multiplicity of ruptured intracranial aneurysms in the Hong Kong Chinese population with subarachnoid haemorrhage. Hong Kong Med J. 2009 Aug;15(4):262-6.

32. Chmayssani M, Rebeiz JG, Rebeiz TJ, Batjer HH, Bendok BR. Relationship of growth to aneurysm rupture in asymptomatic aneurysms $7 \mathrm{~mm}$ : a systematic analysis of the literature. Neurosurgery. 2011 May;68(5):1164-71. https://doi.org/10.1227/NEU.0b013e31820edbd3

33. Rahman M, Ogilvy CS, Zipfel GJ, Derdeyn CP, Siddiqui AH, Bulsara KR, et al. Unruptured cerebral aneurysms do not shrink when they rupture: multicenter collaborative aneurysm study group. Neurosurgery. 2011 Jan;68(1):155-60. https://doi.org/10.1227/NEU.0b013e3181ff357c

34. Mocco J, Komotar RJ, Lavine SD, Meyers PM, Connolly ES, Solomon RA. The natural history of unruptured intracranial aneurysms. Neurosurg Focus. 2004 Nov;17(5):E3. https://doi.org/10.3171/foc. 2004.17.5.3

35. Raymond J, Guillemin F, Proust F, Molyneux AJ, Fox AJ, Claiborne JS, et al.; Trial ON Endovascular Aneurysm Management (TEAM) Collaborative Group. Unruptured intracranial aneurysms. A critical review of the international study of unruptured intracranial aneurysms (isuia) and of appropriate methods to address the clinical problem. Interv Neuroradiol. 2008 Mar;14(1):85-96. https://doi.org/10.1177/159101990801400111

36. Dickey P, Kailasnath P. The diameter-cube hypothesis: a new biophysical model of aneurysm rupture. Surg Neurol. 2002 Sep-Oct;58(3-4):166-73. https://doi.org/10.1016/S0090-3019(02)00848-0 